\title{
Economic evaluation of sirolimus-eluting stents
}

\author{
Fiona M. Shrive, Braden J. Manns, P. Diane Galbraith, Merril L. Knudtson, William A. Ghali; \\ for the APPROACH Investigators
}

ß See related articles pages 323, 361

Abstract

Background: Sirolimus-eluting stents have recently been shown to reduce the risk of restenosis among patients who undergo percutaneous coronary intervention $(\mathrm{PCI})$. Given that sirolimus-eluting stents cost about 4 times as much as conventional stents, and considering the volume of $\mathrm{PCl}$ procedures, the decision to use sirolimus-eluting stents has large economic implications.

Methods: We performed an economic evaluation comparing treatment with sirolimus-eluting and conventional stents in patients undergoing $\mathrm{PCl}$ and in subgroups based on age and diabetes mellitus status. The probabilities of transition between clinical states and estimates of resource use and health-related quality of life were derived from the Alberta Provincial Project for Outcome Assessment in Coronary Heart Disease (APPROACH) database. Information on effectiveness was based on a meta-analysis of randomized controlled clinical trials (RCTs) comparing sirolimus-eluting and conventional stents.

Results: Cost per quality-adjusted life year (QALY) gained in the baseline analysis was Can $\$ 58$ 721. Sirolimus-eluting stents were more cost-effective in patients with diabetes and in those over 75 years of age, the costs per QALY gained being $\$ 44135$ and $\$ 40129$, respectively. The results were sensitive to plausible variations in the cost of stents, the estimate of the effectiveness of sirolimus-eluting stents and the assumption that sirolimus-eluting stents would prevent the need for cardiac catheterizations in the subsequent year when no revascularization procedure was performed to treat restenosis.

Interpretation: The use of sirolimus-eluting stents is associated with a cost per QALY that is similar to or higher than that of other accepted medical forms of therapy and is associated with a significant incremental cost. Sirolimus-eluting stents are more economically attractive for patients who are at higher risk of restenosis or at a high risk of death if a second revascularization procedure were to be required.

CMAJ 2005;172(3):345-51 estenosis is a major limitation to the long-term success of percutaneous coronary intervention (PCI). It is estimated that $14 \%$ of patients who undergo PCI with stent implantation require a second intervention within a year to manage restenosis. ${ }^{1}$ A second coronary procedure carries a significant risk of death or impairment in health-related quality of life (HRQOL). ${ }^{2}$ Moreover, given that approximately 21200 PCIs with stenting were performed in Canada in 1999, restenosis has major economic implications. ${ }^{3}$

Drug-eluting stents are the most recent technologic advance in restenosis prevention. To date, 4 randomized controlled clinical trials (RCTs) have compared the efficacy of sirolimus-eluting stents (the first available drug-eluting stent) and standard uncoated stents in the treatment of de novo native coronary artery disease and published their findings: RAVEL ${ }^{4}$ (RAndomized study with the sirolimuseluting VELocity balloon-expandable stent), SIRIUS ${ }^{5}$ (study of the SIRolImUS-eluting stent), and C-SIRIUS ${ }^{6}$ and E-SIRIUS, the Canadian and European arms of SIRIUS. These trials all found notable reductions in the incidence of radiographic evidence of restenosis and symptomatic restenosis with the use of sirolimus-eluting stents. However, the overall survival rate was not affected. Currently, the cost of sirolimus-eluting stents (about Can $\$ 2900$ per stent) is nearly 4 times that of conventional stents. ${ }^{8}$ Given the volume of PCIs performed annually, decisionmakers must determine their optimal use.

Using a subset of the cohort in the Alberta Provincial Project for Outcome Assessment in Coronary Heart Disease (APPROACH), ${ }^{9}$ we estimated clinical event rates, HRQOL and health care costs for patients undergoing PCI with implantation of a conventional stent. Combining this information with data from the 4 RCTs, we estimated the cost per quality-adjusted life-year (QALY) gained by using sirolimus-eluting stents rather than conventional stents for such patients.

\section{Methods}

All outcome data considered in this analysis were derived from the APPROACH database, a prospective cohort initiative that captures data for all patients undergoing cardiac catheterization in Alberta. The database provides estimates of clinical event rates, HRQOL and costs for all patients with conventional stents, which ensured high-quality input values for our economic evaluation., ${ }^{910}$ Data for the 7334 patients who underwent PCI with implantation of conventional stents between 1998 and 2000 were used to estimate event rates and HRQOL. Because costing data were not available for this cohort, we used data for the 1812 patients who underwent PCI with implantation of conventional stents between 1995 and 1997 to estimate health care costs. 
A Markov process was used to model the cost and clinical outcomes after PCI with stenting in 6-month intervals (Fig. 1; the full model is available in an online appendix [www.cmaj.ca/cgi/content /full/172/3/345/DC1]). A Markov model simulates, on the basis of observed probabilities of transition between discrete clinical states, what would occur over a lifetime in a cohort of patients with the selected treatment. Patients may progress through the following 5 health states after an initial PCI: 1) alive with no clinical restenosis (i.e., event-free), 2) clinical restenosis as determined by the need for a subsequent coronary artery bypass graft (CABG), 3) clinical restenosis as determined by the need for repeat PCI, 4) repeat catheterization with no subsequent revascularization procedure (defined as no PCI or CABG in the ensuing 3 months) and 5) death. Consistent with published literature, restenosis is considered to occur only in the first year after initial PCI. ${ }^{1}$ Thereafter, patients have an ongoing long-term risk of death.

Repeat catheterization with no subsequent revascularization procedure is relatively common and relates to the lack of radiographic evidence of restenosis in the target vessel, feasibility considerations (in the patient or the vessel) despite evidence of restenosis, or preference of the health care provider or the patient (or both). For all such cases, we reviewed the coronary anatomy at the time of repeat angiography and found that the target vessel in the index PCI was more than $50 \%$ occluded in $49.5 \%$ of cases. Thus, in our baseline analysis, we assumed that $49.5 \%$ of repeat catheterizations that were not followed by PCI or CABG would have been avoided if sirolimus-eluting stents had been used.

The risk of death in the first 6 months after the index PCI was determined with use of the 1998-2000 APPROACH cohort. To increase the precision of our estimates of long-term survival after specific events, we used an expanded cohort of 8528 APPROACH patients undergoing conventional stenting in 1995-2000 and analyzed data on death between 6 months and 4 years after PCI in patients in each of the predefined health states, stratified by age and diabetes mellitus status. Given the small numbers of patients in some of the strata, we used a Cox proportional-hazard model to derive hazard ratios (relative risks) for death in specific strata during the subsequent 3.5 years compared with patients under the age of 65 without diabetes. To account for increasing age-related mortality after 4 years, we multiplied the hazard ratios for each stratum by the age-specific increment in mortality risk of the Canadian population. ${ }^{11}$

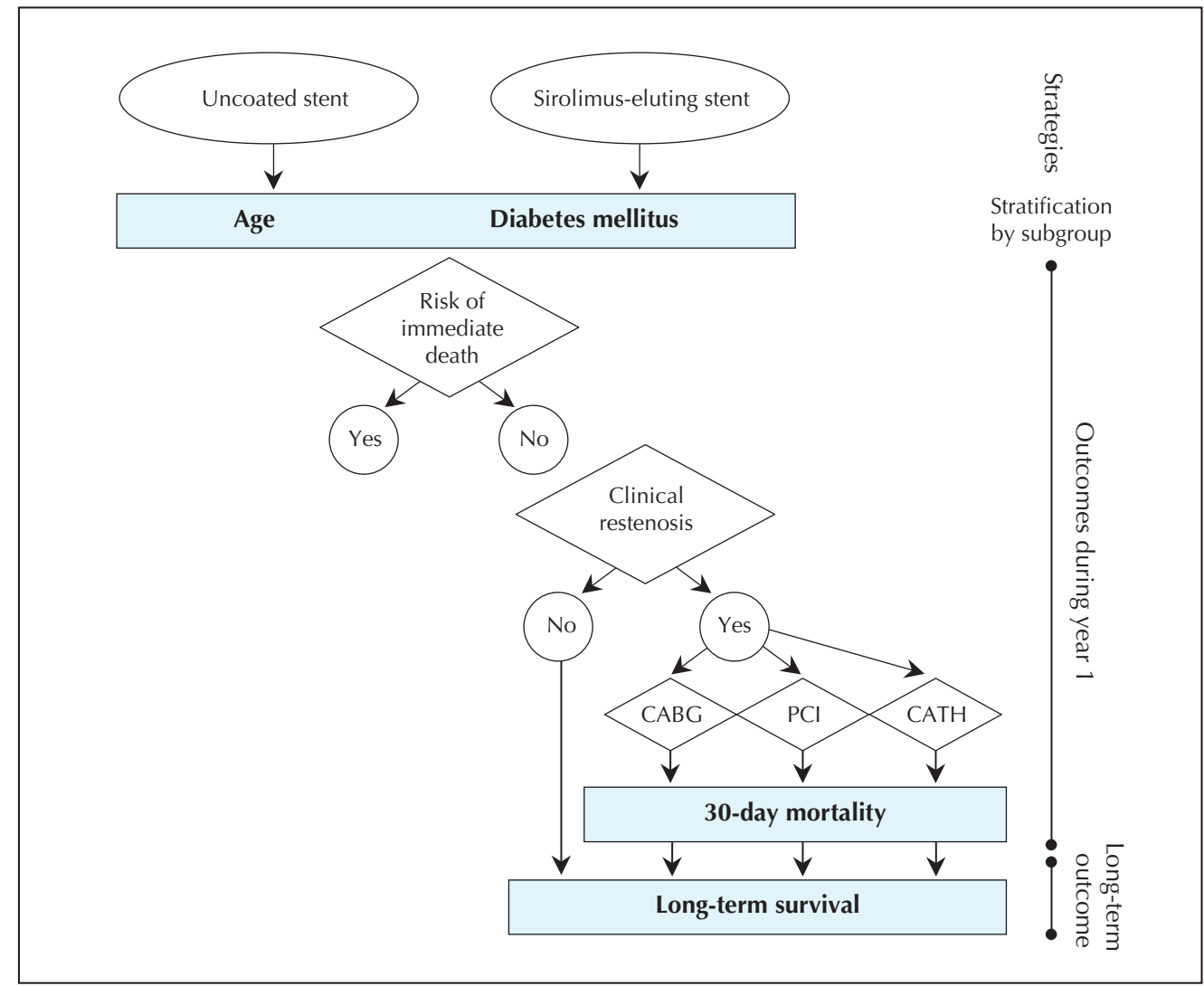

Fig. 1: Markov model, showing cost and clinical outcomes after percutaneous coronary intervention $(\mathbf{P C I})$ with stenting in 6-month intervals. After initial $\mathrm{PCl}$, patients are at risk of clinical restenosis over the first year. During this year, they may progress through 5 discrete health states: 1) alive with no clinical restenosis (i.e., event-free), 2) clinical restenosis as determined by the need for a subsequent coronary artery bypass graft (CABG), 3) clinical restenosis as determined by the need for repeat $\mathrm{PCl}, 4$ ) repeat catheterization with no subsequent revascularization procedure (defined as no PCl or CABG in the ensuing 3 months) and 5) death. Restenosis is considered to occur only in the first year after initial $\mathrm{PCl} .^{1}$ Thereafter, patients have an ongoing long-term risk of death. $\mathrm{CATH}=$ catheterization. 
Because there is no apparent effect on mortality, ${ }^{4-7}$ other than possibly that related to eliminating the immediate risk associated with a second procedure (catheterization, PCI or CABG), the main benefit of sirolimus-eluting stents may be the avoidance of the costs associated with repeat procedures and possibly improved HRQOL, since repeat procedures have the potential to reduce

Table 1: Baseline characteristics, event rates and health care costs of patients in the Alberta Provincial Project for Outcome Assessment in Coronary Heart Disease (APPROACH) who underwent initial percutaneous coronary intervention (PCI) with implantation of a bare metal stent

\begin{tabular}{|c|c|c|c|c|c|c|}
\hline \multirow[b]{2}{*}{ Variable } & \multirow[b]{2}{*}{ Overall cohort } & \multicolumn{3}{|c|}{ Age, yr } & \multicolumn{2}{|c|}{ Diabetes mellitus status } \\
\hline & & $<65$ & $65-75$ & $>75$ & No diabetes & Diabetes \\
\hline 1998-2000 cohort & $n=7334$ & $n=4429$ & $n=2005$ & $n=900$ & $n=6015$ & $n=1319$ \\
\hline \multicolumn{7}{|l|}{ Baseline characteristics } \\
\hline Age, yr, mean (SD) & $61.5(11.6)$ & $53.9(7.7)$ & $70.2(2.8)$ & $79.6(3.2)$ & $61.2(11.7)$ & $63.0(11.2)$ \\
\hline Sex, male, \% & 70.9 & 80.9 & 68.3 & 58.2 & 67.7 & 76.2 \\
\hline Diabetes mellitus present, \% & 18.0 & 16.7 & 20.2 & 19.4 & - & - \\
\hline \multicolumn{7}{|l|}{ Indication, \% } \\
\hline Acute myocardial infarction & 46.9 & 48.6 & 43.2 & 46.7 & 47.2 & 45.7 \\
\hline Unstable angina & 27.3 & 25.5 & 26.1 & 33.1 & 26.9 & 29.3 \\
\hline Stable angina & 19.9 & 20.1 & 20.1 & 14.2 & 19.9 & 20.1 \\
\hline Other & 5.9 & 5.8 & 10.6 & 6.0 & 6.0 & 4.9 \\
\hline $\begin{array}{l}\text { Use of glycoprotein IIB/IIIA inhibitors, \% } \\
\text { Event rates, \% }\end{array}$ & 46.4 & 47.6 & 46.0 & 41.1 & 46.2 & 46.9 \\
\hline Death within $7 \mathrm{~d}$ after initial $\mathrm{PCI}$ & 1.1 & 0.6 & 1.2 & 3.1 & 1.0 & 1.4 \\
\hline \multicolumn{7}{|l|}{$\begin{array}{l}\text { Repeat catheterization for restenosis } \\
\text { within } 12 \text { mo after index } \mathrm{PCl}\end{array}$} \\
\hline $\begin{array}{l}\text { With revascularization procedure } \\
\text { (and proportion with CABG as } \\
\text { second procedure) }\end{array}$ & $8.2(28.0)$ & $8.5(21.9)$ & $8.1(32.1)$ & $7.0(17.4)$ & $7.8(28.1)$ & $9.9(27.9)$ \\
\hline Without revascularization procedure & 12.2 & 12.6 & 11.6 & 11.2 & 11.9 & 13.5 \\
\hline Death in first $6 \mathrm{mo}$ & 1.4 & 0.8 & 1.8 & 3.6 & 1.3 & 1.7 \\
\hline \multicolumn{7}{|l|}{$\begin{array}{l}\text { For patients with repeat catheterization, } \\
\text { death within } 30 \mathrm{~d}\end{array}$} \\
\hline After CABG & 3.1 & 1.8 & 3.6 & 5.6 & 2.9 & 3.8 \\
\hline After repeat $\mathrm{PCl}$ & 1.4 & 0.7 & 1.8 & 3.3 & 1.2 & 2.0 \\
\hline Without revascularization procedure & 1.8 & 0.9 & 2.0 & 4.7 & 1.5 & 3.0 \\
\hline Subsequent annual mortality rate* & 1.4 & 0.7 & 2.0 & 3.4 & 1.5 & 3.1 \\
\hline \multicolumn{7}{|l|}{ EUROQOL EQ-5D utility scores } \\
\hline Event† & 0.77 & 0.77 & 0.79 & 0.74 & 0.78 & 0.72 \\
\hline Event-free & 0.85 & 0.86 & 0.84 & 0.78 & 0.86 & 0.78 \\
\hline 1995-97 cohort & $n=1812$ & $n=1134$ & $n=508$ & $n=170$ & $n=1551$ & $n=261$ \\
\hline \multicolumn{7}{|l|}{$\begin{array}{l}\text { Mean costs in } 2002 \text { Canadian dollars } \\
\text { (and interquartile range) }\end{array}$} \\
\hline \multicolumn{7}{|l|}{ Year 1} \\
\hline Event-free & $\begin{array}{c}5195 \\
(2079-5733)\end{array}$ & $\begin{array}{c}4297 \\
(1773-4648)\end{array}$ & $\begin{array}{c}6168 \\
(2737-6515)\end{array}$ & $\begin{array}{c}8047 \\
(3400-8787)\end{array}$ & $\begin{array}{c}4948 \\
(2055-5379)\end{array}$ & $\begin{array}{c}6736 \\
(2459-7426)\end{array}$ \\
\hline CABG $\neq$ & $\begin{array}{c}32009 \\
(20750-40072)\end{array}$ & - & - & - & - & - \\
\hline Repeat PCI & $\begin{array}{c}15569 \\
(8870-17343)\end{array}$ & - & - & - & - & - \\
\hline $\begin{array}{l}\text { Repeat catheterization without } \\
\text { revascularization procedure } \neq\end{array}$ & $\begin{array}{l}12591 \\
(5603-15114)\end{array}$ & - & - & - & - & - \\
\hline Year 2 & $\begin{array}{c}3226 \\
(401-3142)\end{array}$ & $\begin{array}{c}2634 \\
(244-2376)\end{array}$ & $\begin{array}{c}4224 \\
(1136-4229)\end{array}$ & $\begin{array}{c}4188 \\
(1290-4560)\end{array}$ & $\begin{array}{c}2860 \\
(371-2903)\end{array}$ & $\begin{array}{c}5398 \\
(778-5173)\end{array}$ \\
\hline Year 3 & $\begin{array}{c}2337 \\
(336-2525)\end{array}$ & $\begin{array}{c}1819 \\
(211-1957)\end{array}$ & $\begin{array}{c}3354 \\
(977-3144)\end{array}$ & $\begin{array}{c}2756 \\
(911-3557)\end{array}$ & $\begin{array}{c}2141 \\
(306-2355)\end{array}$ & $\begin{array}{c}3502 \\
(809-3628)\end{array}$ \\
\hline Year 4 & $\begin{array}{c}1775 \\
(231-2189)\end{array}$ & $\begin{array}{c}1410 \\
(158-1672)\end{array}$ & $\begin{array}{c}2295 \\
(756-2762)\end{array}$ & $\begin{array}{c}2662 \\
(766-2820)\end{array}$ & $\begin{array}{c}1651 \\
(223-2031)\end{array}$ & $\begin{array}{c}2516 \\
(293-2938)\end{array}$ \\
\hline
\end{tabular}

Note: $\mathrm{SD}=$ standard deviation, $\mathrm{CABG}=$ coronary artery bypass grafting.

*Estimated within our model by multiplying the baseline mortality rate by the appropriate Cox proportional-hazard ratio.

†Defined as the need for repeat catheterization, whether or not a revascularization procedure was performed.

$\ddagger$ Costs were estimated by health state in year 1 and on the basis of age and diabetes status in subsequent years. 
HRQOL. HRQOL was estimated in 1954 patients of the APPROACH 1998-2000 cohort from self-reported EuroQol EQ-5D utility scores obtained 1 year after catheterization. Mean

\section{Table 2: Cost-utility of sirolimus-eluting stents, overall and according to age and diabetes status}

\begin{tabular}{|c|c|c|c|}
\hline Patient group & $\begin{array}{l}\text { Incremental } \\
\text { cost, }{ }^{*} \text { Can } \$\end{array}$ & $\begin{array}{c}\text { Incremental } \\
\text { utility, } \uparrow \text { QALY }\end{array}$ & $\begin{array}{c}\text { Incremental } \\
\text { cost-utility ratio, } \neq \\
\text { Can\$/QALY }\end{array}$ \\
\hline Overall & 2500 & 0.04 & 58721 \\
\hline \multicolumn{4}{|l|}{ Age, yr } \\
\hline$<65$ & 2600 & 0.04 & 72464 \\
\hline $65-75$ & 2400 & 0.05 & 47441 \\
\hline$>75$ & 2600 & 0.07 & 40129 \\
\hline \multicolumn{4}{|l|}{ Diabetes status } \\
\hline No diabetes & 2500 & 0.04 & 63383 \\
\hline Diabetes & 2400 & 0.06 & 44135 \\
\hline
\end{tabular}

Note: QALY = quality-adjusted life-year.

*The average additional cost per patient associated with implanting a sirolimus-eluting stent rather than a conventional, uncoated stent. The costs considered include the immediate cost of the stent and the procedure, as well as future health care costs incurred by patients with either type of stent.

†The average QALY gained per patient.

$\ddagger$ The additional expenditure required to gain 1 QALY. utility scores were calculated for patients in each age/diabetes stratum. Given that patients undergoing repeat procedures in our data reported similar reductions in HRQOL regardless of the type of procedure, the procedure-specific scores were combined to produce a "combined-event" utility score. Given that longterm HRQOL is unlikely to be impaired by a short-term procedure, patients who underwent a second procedure received the combined-event utility score only for the first year in our baseline analysis. After year 1, HRQOL is assumed to be the same for patients in all of the health states.

For the economic analysis, we adopted a health care payer perspective. The outcomes considered were costs and QALYs over a patient's lifetime. Costs and outcomes were discounted by $3 \%$ per year. ${ }^{12}$ Data on costs were obtained from Alberta Health and Wellness (the sole payer for hospital and physician care in Alberta) for the 1995-1997 APPROACH cohort. Costs were categorized as hospital care, ambulatory care, home care, physician claims and medication costs and were available to March 2001. Ambulatory care costs were restricted to cardiac care. Annual costs were estimated from the date of the index PCI and were converted to 2002 Canadian dollars by applying a yearly inflation factor. ${ }^{13}$ Given that costs were relatively constant during years 3 and 4 , we assumed that annual costs remained constant after the 4-year period.

We estimated the cost for each sirolimus-eluting and conven-

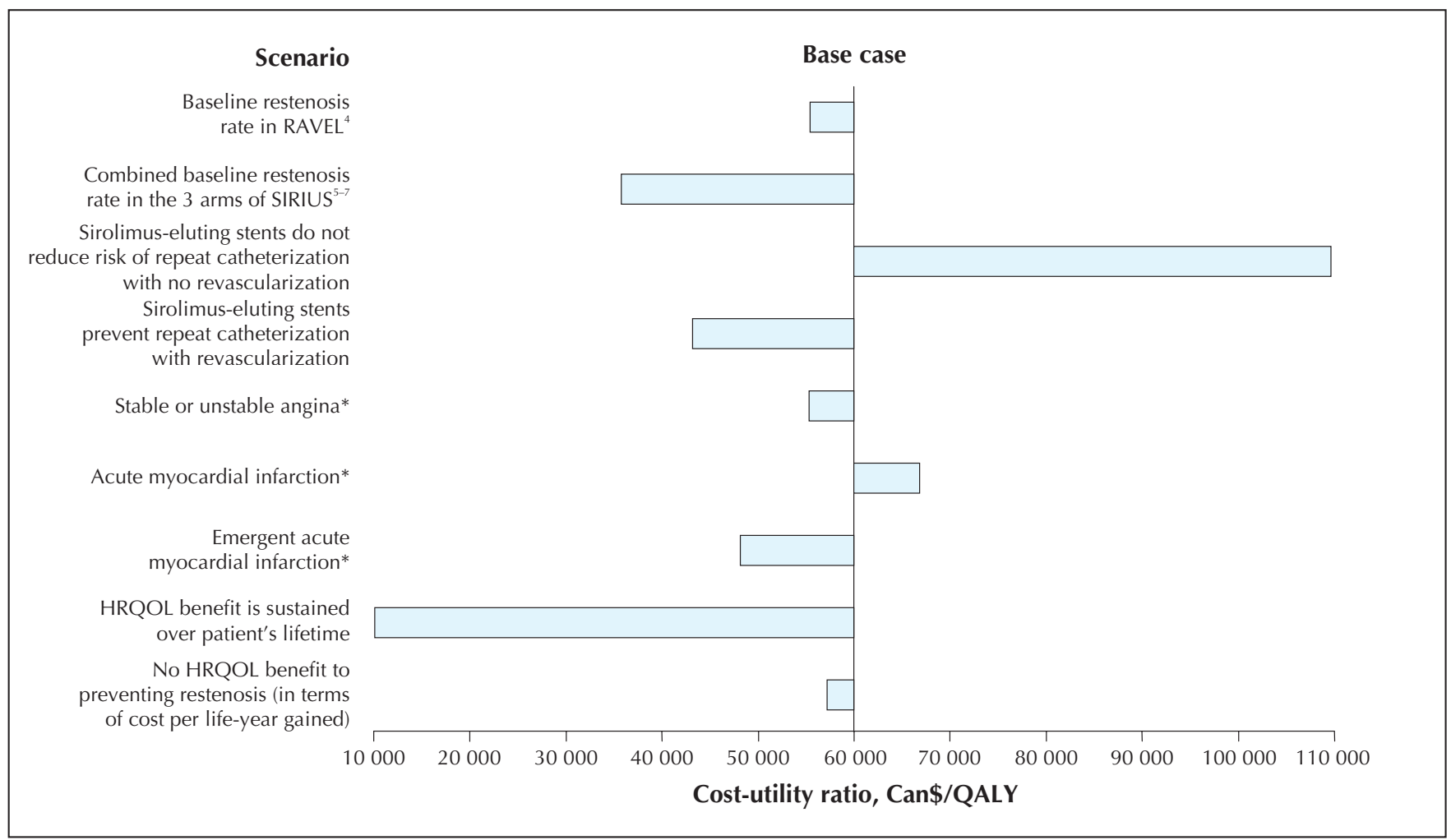

Fig. 2: Scenario analyses. All analyses compare the base case, in which the cost per quality-adjusted life-year (QALY) gained with the use of a sirolimus-eluting stent rather than a conventional stent with $\mathrm{PCl}$ is Can $\$ 58721$. Each horizontal bar represents the cost per QALY gained in the described scenario, in which 1 or more input values is varied. For example, if the baseline restenosis rate is changed to the RAVEL (RAndomized study with the sirolimus-eluting VELocity balloon-expandable stent ${ }^{4}$ ) restenosis rate, the cost per QALY decreases to \$54 176. *Varying estimates of 7-day mortality and clinical-event rates in patients in the cohort of the Alberta Provincial Project for Outcome Assessment in Coronary Heart Disease (APPROACH). SIRIUS = study of the SIRolImUS-eluting stent, ${ }^{5} \mathrm{HRQOL}=$ health-related quality of life. 
tional stent at Can\$2900 and Can\$500, respectively. ${ }^{8}$ In the baseline analysis, we used an average of 1.4 stents per PCI (the number of conventional stents used per patient in the APPROACH cohort). The cost of care during the initial hospital stay was otherwise assumed to be the same for each type of stent. Future health care costs for patients receiving sirolimus-eluting stents are likely to be reduced as a result of fewer second procedures, the costs of which were assumed to be equal for patients originally treated with either type of stent.

The cost per QALY gained with the implantation of a sirolimus-eluting stent rather than a conventional stent was calculated for all patients undergoing PCI, as an overall group and in subgroups based on age and diabetes status.

To determine the efficacy of sirolimus-eluting stents, we performed a meta-analysis of the data from the 4 RCTs. ${ }^{4-7}$ The resulting pooled estimate (random-effects model) of 0.23 for the relative risk of clinical restenosis was, in the baseline analysis, applied to reduce the probability of a second procedure (catheterization, PCI or CABG). Methodologic details are included in the online appendix (www.cmaj.ca/cgi/content/full/172/3/345/DC1).

To examine the impact of the various assumptions required to run the Markov model, we completed various scenario and sensitivity analyses. Full methodologic details are available in the online appendix.

\section{Results}

Table 1 displays the baseline characteristics, clinical outcomes, including mortality and HRQOL (EQ-5D utility scores), and costs of care for the APPROACH cohort of patients with conventional stents. The mean age of the overall cohort was 61.5 years, and $18.0 \%$ of the cohort reported having diabetes. As expected, mortality increased with age and diabetes status. The EQ-5D utility scores were higher among event-free patients than among patients who underwent a second procedure to manage restenosis (overall cohort, 0.85 v. $0.77, p<0.001$ ).

The results of the baseline cost-utility analysis are presented in Table 2. The cost per QALY gained by implanting a sirolimus-eluting stent rather than a conventional stent was Can\$58 721. The use of sirolimus-eluting stents was more economically attractive in older patients and in patients with diabetes, owing in part to a higher risk of death associated with second procedures in these patients.

Our analysis was robust to plausible alternative scenarios (Fig. 2). However, when we considered a scenario in which sirolimus-eluting stents did not reduce the frequency of repeat catheterization with no revascularization procedure, the cost per QALY gained rose to \$108 340 .

The results of the other one-way sensitivity analyses are shown in Table 3. The cost per QALY of sirolimus-eluting stents varied with the estimate of efficacy: when the efficacy estimate was varied within a plausible range (relative risk 0.01-0.55), the cost per QALY ranged from \$39 777 to $\$ 119280$. When the clinical restenosis rate was increased by $50 \%$ and by $100 \%$, the cost per QALY improved to \$33 723 and \$21312, respectively. The cost per QALY also improved when the cost of sirolimus-eluting stents was decreased by 25\% (\$35 082) or 50\% (\$11 443).

Fig. 3 presents the results of a scenario analysis simulating more closely a US health care setting. When the costs of care were increased by $50 \%$ and the restenosis rate was varied, the cost per QALY gained decreased to Can\$23 831. Applying in addition the 30-day mortality rates associated with CABG and PCI that have been reported in US settings, ${ }^{14,15}$ the cost per QALY gained decreased to Can $\$ 17741$.

\section{Table 3: Sensitivity analysis*}

\begin{tabular}{|c|c|}
\hline Variable & $\begin{array}{c}\text { Incremental cost } \\
\text { per QALY gained, } \\
\text { Can } \$ / Q A L Y\end{array}$ \\
\hline Base case & 58721 \\
\hline \multicolumn{2}{|l|}{ 30-d mortality rate after second procedure } \\
\hline Increased $50 \%$ & 40838 \\
\hline Decreased $50 \%$ & 106445 \\
\hline \multicolumn{2}{|l|}{ CABG rate } \\
\hline Increased 25\% & 55379 \\
\hline Decreased 25\% & 62309 \\
\hline \multicolumn{2}{|l|}{ Clinical restenosis rate $†$} \\
\hline Decreased 25\% (to $10.7 \%$ ) & 83801 \\
\hline Increased 50\% (to $21.3 \%$ ) & 33723 \\
\hline Increased $100 \%$ (to $28.4 \%$ ) & 21312 \\
\hline $\begin{array}{l}\text { Assuming patients undergoing a second } \mathrm{PCl} \\
\text { receive a sirolimus-eluting stent }\end{array}$ & 56187 \\
\hline \multicolumn{2}{|l|}{$\begin{array}{l}\text { Difference in EQ-5D scores between event } \\
\text { and event-free groups }\end{array}$} \\
\hline Increased 50\% & 55169 \\
\hline Decreased 50\% & 62760 \\
\hline \multicolumn{2}{|l|}{ Subsequent mortality rate } \\
\hline Upper $95 \% \mathrm{Cl}$ & 62507 \\
\hline Lower $95 \% \mathrm{Cl}$ & 55398 \\
\hline $\begin{array}{l}\text { Efficacy of sirolimus-eluting stents: relative risk } \\
\text { from meta-analysis with fixed- effects model }(0.21)\end{array}$ & 56996 \\
\hline Lower $95 \% \mathrm{Cl}$ in RAVEL (0.01) & 39777 \\
\hline Upper 95\% CI in SIRIUS (0.55) & 119280 \\
\hline \multicolumn{2}{|l|}{ Cost of sirolimus-eluting stents } \\
\hline Increased 25\% & 82359 \\
\hline Reduced 25\% & 35082 \\
\hline Reduced 50\% & 11443 \\
\hline \multicolumn{2}{|l|}{ Average number of stents per procedure } \\
\hline Increased $25 \%$ & 78284 \\
\hline Decreased 25\% & 39157 \\
\hline \multicolumn{2}{|l|}{ Discount } \\
\hline None & 44691 \\
\hline $5 \%$ rate & 68573 \\
\hline $6 \%$ rate & 73582 \\
\hline
\end{tabular}

Note: $\mathrm{Cl}=$ confidence interval, $\mathrm{RAVEL}=\mathrm{RAndomized} \mathrm{study} \mathrm{with} \mathrm{the} \mathrm{sirolimus-eluting}$ VELocity balloon-expandable stent, ${ }^{4}$ SIRIUS $=$ study of the SIRollmUS-eluting stent. ${ }^{5}$ *Full methodologic details are available in the online appendix (www.cmaj.ca/cgi/content /full/172/3/345/DC1).

†Estimated for the base case as the rate of restenosis followed by repeat $\mathrm{PCI}$ or $\mathrm{CABG}(8.2 \%)$ combined with the rate of repeat catheterization not followed by a revascularization procedure $(12.0 \%)$, when $49.5 \%$ of the latter instances of restenosis were considered preventable $(8.2 \%+6.0 \%=14.2 \%)$. 


\section{Interpretation}

In the baseline analysis, the overall cost per QALY gained with the implantation of sirolimus-eluting stents was Can\$58 721; the cost varied from \$40 129 to $\$ 72464$ among the subgroups based on age and diabetes status. The use of these stents appeared to be more economically attractive in older patients and in those with diabetes, owing to a combination of factors, the most important being the higher 30-day mortality associated with second procedures in these subgroups; this finding is consistent with the results from a preliminary short-term cost-effectiveness analysis performed in the US setting. ${ }^{16}$ When the clinical restenosis rate was increased by $50 \%$ and $100 \%$, as in patients with more complex lesions, ${ }^{1}$ the cost per QALY was reduced to $\$ 33723$ and $\$ 21312$, respectively.

It seems reasonable to compare the cost per QALY associated with sirolimus-eluting stents and the cost per QALY of other commonly funded forms of therapy. Published estimates of cost per QALY gained for CABG range from Can $\$ 13200$ to $\$ 100000 .{ }^{17-19}$ For cardiac defibrillators when implanted in cardiac arrest survivors with a low ejection fraction the estimated cost per QALY is $\$ 75000,{ }^{17-20}$ and for intensive glycemic control in patients with type 2 diabetes the estimated cost per QALY is $\$ 41384 .{ }^{21}$ The cost per QALY associated with sirolimus-eluting stents in our analysis (\$58 721) is comparable, although it is higher than that of many economically efficient forms of medical therapy (e.g., intensive hypertension control in patients with type 2 diabetes [about $-\$ 1959$ per QALY]). ${ }^{21}$
Our analysis was sensitive to the estimate considered for the efficacy of sirolimus-eluting stents, which suggests that more research is needed into the effectiveness of these stents in preventing "clinical restenosis." In addition, our analysis was sensitive to whether these stents prevented repeat catheterizations that were not followed by revascularization procedures: when we assumed that such procedures were not prevented by sirolimus-eluting stents, the cost per QALY increased to $\$ 108340$.

Since we could not derive actual outcomes associated with complex lesions from our patient cohort, our sensitivity analysis presented a scenario with estimated rates of clinical restenosis similar to those reported specifically for patients with complex lesions. ${ }^{22}$ The cost per QALY improved to $\$ 21312$ when only patients with complex lesions were considered. This raises the possibility of selected use of sirolimus-eluting stents for only such patients, a strategy that anecdotal reports suggest may already be operating in some Canadian centres. If such a policy were to be formally implemented, explicit criteria for defining "complex" lesions would need to be derived and possibly audited.

Drug-eluting stents are a promising technologic advance in reducing the risk of restenosis after PCI. However, given the large potential population of eligible patients and the high cost of sirolimus-eluting stents, it is important to consider the impact on both clinical outcomes and costs. These data will inform decisions on reimbursement and on patient selection. The use of sirolimus-eluting stents in PCI patients, particularly those at higher risk of restenosis or at high risk of death if a second revascularization procedure

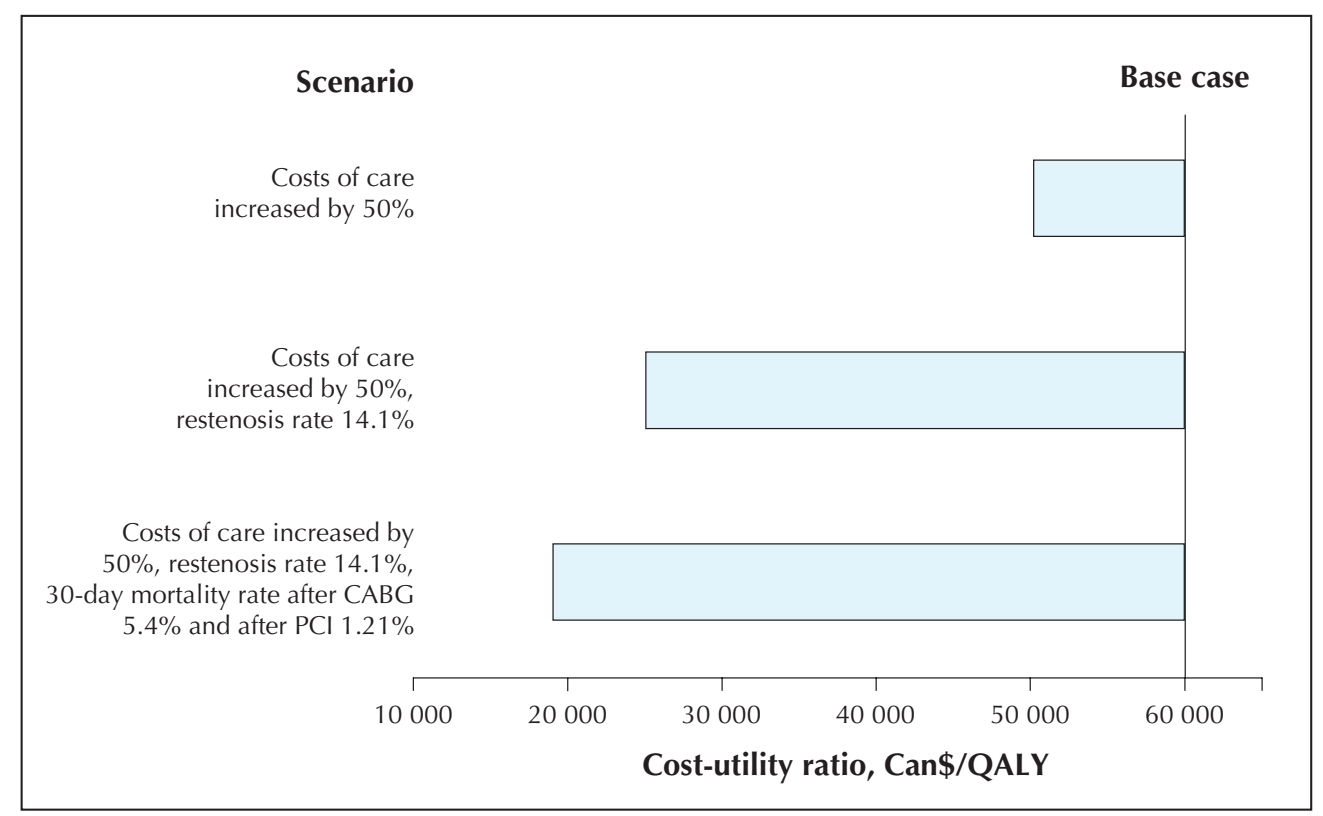

Fig. 3: Scenario analysis simulating more closely a US health care setting. In addition to increasing the costs of care by $50 \%$, the restenosis rate and the 30-day mortality associated with CABG and PCI were changed to those reported in US settings (shown in the figure). In the baseline analysis, the restenosis rate was $14.2 \%$, the 30 -day mortality after CABG $3.1 \%$ and the 30 day mortality after $\mathrm{PCl} 1.4 \%$. 
were to be required, is associated with a cost-effectiveness ratio similar to those of other accepted medical forms of therapy. The use of these stents has an incremental cost and, in the absence of a budget increase, would require resources from other health care sectors.

\section{This article has been peer reviewed.}

From the Departments of Community Health Sciences (Shrive, Manns, Galbraith, Ghali) and Medicine (Manns, Knudtson, Ghali), the Centre for Health and Policy Studies (Shrive, Manns, Galbraith, Ghali) and the Division of Cardiology (Knudtson), University of Calgary, Calgary, Alta.

Merril Knudtson is the principal investigator of the Alberta Provincial Project for Outcome Assessment in Coronary Heart Disease (APPROACH).

\section{Competing interests: None declared.}

Contributors: All of the authors participated in the study conception and design and the data analysis. Merril Knudtson proposed the research question and provided clinical content and expertise. Diane Galbraith provided clinical content and expertise as well as data analysis. Braden Manns and William Ghali supervised all aspects of the economic evaluation and contributed to the modelling process. Fiona Shrive completed the economic evaluation and data analysis. All of the authors contributed to the writing of the manuscript and approved the final version.

Acknowledgements: Fiona Shrive is supported by a Canada Graduate Scholarship from the Canadian Institutes of Health Research (CIHR) and an Alberta Heritage Foundation for Medical Research Studentship. In addition, she and Diane Galbraith are supported by a Canadian Cardiovascular Outcomes Research Team Student Research Fellowship, which is funded by CIHR and the Heart and Stroke Foundation of Canada, and a TORCH (Tomorrow's Research Cardiovascular Health Professionals) Student Fellowship. Braden Manns is supported by a CIHR New Investigator Award. Merril Knudtson receives support from the Libin Trust Fund. William Ghali is funded by a Government of Canada Research Chair in Health Services Research and by a Health Scholar Award from the Alberta Heritage Foundation for Medical Research.

The Alberta Provincial Project for Outcome Assessment in Coronary Heart Disease (APPROACH) was initially funded with a grant from the W. Garfield Weston Foundation. Ongoing operation has been made possible by operating grants from the Heart and Stroke Foundation of Alberta, the Northwest Territories and Nunavut and from CIHR. The initiative has also received contributions from Alberta Health and Wellness, Merck Frosst Canada Ltd., Monsanto Canada Inc.-Searle, Eli Lilly Canada Inc., Guidant Corporation, Boston Scientific Ltd., Hoffmann-LaRoche Ltd. and Johnson \& Johnson-Cordis Corporation. These unrestricted grants provide the project with "general use" funds that support the cardiac registry's infrastructure. The funding provided by Johnson \& Johnson is not linked to any specific data analysis.

\section{References}

1. Cutlip DE, Chauhan MS, Baim DS, Ho KKL, Popma JJ, Carrozza JP, et al. Clinical restenosis after coronary stenting: perspectives from multicenter clinical trials. 7 Am Coll Cardiol 2002;40:2082-9.

2. Weaver WD, Reisman MA, Griffin JJ, Buller CE, Leimgruber PP, Henry T. Optimum percutaneous transluminal coronary angioplasty compared with routine stent strategy trial (OPUS-1): a randomised trial. Lancet 2000;355: 2199-203.

3. Jamal SM, Shrive FM, Ghali WA, Knudtson ML, Eisenberg MJ, for the Canadian Cardiovascular Outcomes Research Team (CCORT). In-hospital outcomes after percutaneous coronary intervention in Canada: 1992/93 to 2000/01. Can 7 Cardiol 2003;19:782-9.
4. Morice MC, Serruys PW, Sousa JE, Fajadet J, Ban Hayashi E, Perin M, et al A randomized comparison of a sirolimus-eluting stent with a standard stent for coronary revascularization. $N$ Engl 7 Med 2002;346:1773-80.

5. Moses JW, Leon MB, Popma JJ, Fitzgerald PJ, Holmes DR, O'Shaughnessy $\mathrm{C}$, et al. Sirolimus-eluting stents versus standard stents in patients with stenosis in a native coronary artery. $N$ Engl 7 Med 2003:349:1315-23.

6. Schampaert E, Cohen EA, Schluter M, Reeves F, Traboulsi M, Title LM, et al, for the C-SIRIUS Investigators. The Canadian study of the sirolimuseluting stent in the treatment of patients with long de novo lesions in small native coronary arteries (C-SIRIUS). 7 Am Coll Cardiol 2004;43:1110-5.

7. Schofer J, Schluter M, Gershlick AH, Wijns W, Garcia E, Schampaert E, et al; E-SIRIUS investigators. Sirolimus-eluting stents for treatment of patients with long atherosclerotic lesions in small coronary arteries: double-blind, randomised controlled trial (E-SIRIUS). Lancet 2003;362:1093-9.

8. Reimbursement and coding guidelines for drug-eluting stents. Johnson \& Johnson-Cordis Corporation; 2003. Available: www.cordis.com/active/crdus /en_US/html/cordis/downloads/DES guide.pdf (accessed 2004 Nov 24).

9. Ghali WA, Knudtson ML, on behalf of the APPROACH investigators Overview of the Alberta Provincial Project for Outcome Assessment in Coronary Heart Disease. Can 7 Cardiol 2000;16:1225-30.

10. Norris CM, Ghali WA, Knudtson ML, Saunders LD, Naylor CD. Dealing with missing data in observational health care outcome analysis. 7 Clin Epidemiol 2000;53:377-83.

11. Annual demographic statistics. Ottawa: Statistics Canada; cat no 91-213-XIB

12. Canadian Coordinating Office for Health Technology Assessment (CCOHTA) Guidelines for economic evaluations of pharmaceuticals. 2nd ed. Ottawa: CCOHTA; 1997. p. 4.

13. Consumer price index, July 2004. The Daily [Statistics Canada];2004 Aug 24. Available: www.statcan.ca/Daily/English/040824/d040824a.htm (accessed 2004 Dec 9).

14. Goodney PP, O'Connor GT, Wennberg DE, Birkmeyer JD. Do hospitals with low mortality rates in coronary artery bypass also perform well in valve replacement? Ann Thorac Surg 2003;76:1131-7.

15. Malenka DJ, Wennberg DE, Quinton HA, O'Rourke DJ, McGrath PD, Shubrooks SJ, et al, for the Northern New England Cardiovascular Disease Study Group. Gender-related changes in practice and outcomes of percutaneous coronary interventions in northern New England from 1994 to 1999.7 Am Coll Cardiol 2002;40:2092-101.

16. Greenberg D, Bakhai A, Cohen DJ. Can we afford to eliminate restenosis? Can we afford not to? J Am Coll Cardiol 2004;43:513-8.

17. The CEA registry: standardizing the methods and practices of cost-effectiveness analysis [Web site of Harvard Center for Risk Analysis, Harvard School of Public Health, Boston]. Available: www.hsph.Harvard.edu/cearegistry (accessed 2004 Nov 24).

18. Pliskin JS, Stason WB, Weinstein MC, Johnson RA, Cohn PF, McEnany MT, et al. Coronary artery bypass graft surgery: clinical decision making and cost-effectiveness analysis. Med Decis Making 1981;1(1):10-28.

19. Weinstein MC, Stason WB. Cost-effectiveness of coronary-artery bypass surgery. Circulation 1982;66(3 Suppl):III56-III66.

20. Owens DK, Sanders GD, Harris RA, McDonald KM, Heidenreich PA, Dembitzer $\mathrm{AD}$, et al. Cost-effectiveness of implantable cardioverter defibrillators relative to amiodarone for prevention of sudden cardiac death. Ann Intern Med 1997;126:1-12.

21. CDC Diabetes Cost-effectiveness Group. Cost-effectiveness of intensive glycemic control, intensified hypertension control, and serum cholesterol level reduction for type 2 diabetes. FAMA 2002;287:2542-51.

22. Giedd KN, Bergmann SR. Myocardial perfusion imaging following percutaneous coronary intervention: the importance of restenosis, disease progression, and directed reintervention. 7 Am Coll Cardiol 2004:43:328-36.

Correspondence to: Dr. William A. Ghali, Rm. HSG239,

3330 Hospital Dr. NW, Calgary AB T2N 4N1;

fax 403 210-3818; wghali@ucalgary.ca 